\title{
LA REPRESENTACION DE LOS AYUNTAMIENTOS EN LAS MANCOMUNIDADES. A PROPOSITO DE LAS SENTENCIAS DEL TRIBUNAL SUPREMO DE 9 DE SEPTIEMBRE Y 5 DE DICIEMBRE DE 1988
}

\author{
POR
}

IgnaCio PEMÁN Gavín

SUMARIO: I. Preámbulo.-ll. La representación de los Ayuntamientos en las Mancomunidades en la jurisprudencia del Tribunal Supremo.-III. El derecho de los concejales que constituyen minoria en el planteamiento del Tribunal Constitucional.IV. Conclusión.

\section{PREAMBULO}

Como es sabido, la institución representativa ha sido objeto de una continuada elaboración doctrinal por parte del Tribunal Constitucional con motivo de los diversos supuestos de conculcación del art. 23 de nuestra Norma Fundamental (1).

Pero, seguramente, es en la sentencia 32/85, de 6 de marzo (2), donde confluyen de forma más evidente, el principio constitucional de pluralismo político, y la institución representativa como instrumento de efectividad del derecho de los electores a participar en los asuntos públicos (3); planteamiento que le llevó al Tribunal Constitucional a dotar de relevancia jurídica a la adscrip-

(1) Cabe recordar, por su importancia en la configuración del concepto de representación politica las sentencias del Tribunal Constitucional 40/1981, de 18 de diciembre; 5/1983, de 4 de febrero; 10/1983, de 21 de febrero; 16/1984, de 6 de febrero; 18/1984, de 7 de febrero; 23/1984, de 20 de febrero; 23/1985, de 6 de marzo; 75/1985, de 21 de junio. Parte de ellas han tenido como marco el ámbito municipal, ámbito al que el Tribunal Constitucional ha hecho totalmente aplicable dicho concepto, aunque no sin voces disonantes dentro del Tribunal. En este sentido discrepante véase el importante voto particular que formularon los Magistrados don Angel Latorre Segura, don Manuel Díez de Velasco Vallejo y don Luis Díez-Picazo y Ponce de León a la sentencia 10/1983, de 21 de febrero.

(2) En dicha sentencia el Tribunal Constitucional conoció de un recurso de amparo interpuesto inicialmente con motivo del acuerdo del Ayuntamiento de La Guardia sobre la constitución y composición de las Comisiones Informativas municipales y en virtud del cual se asignó a los cinco concejales de los grupos de oposición la Comisión de Sanidad y Beneficencia, excluyendo su participación en el resto de las Comisiones. El Tribunal Constitucional otorgó el amparo y anuló el citado acuerdo plenario del Ayuntamiento de La Guardia reconociendo el derecho de los recurrentes a que la composición de las Comisiones se acomodara al criterio de proporcionalidad.

(3) Francisco J. BASTIDA FREIJEDO, en su artículo «Derecho de participación a través de representantes y función constitucional de los partidos políticos». Revista Española de Derecho Constitucional, núm. 21, septiembre-diciembre 1987, analiza con profundidad la elaboración de una concepción democrática de la institución representativa en el Tribunal Constitucional. 
ción política de los represetantes, y en consecuencia de un contenido propio a los representantes que constituyen minoría.

Dicha elaboración jurisprudencial, ha dado pie a que, con motivo de diversos recursos interpuestos por representantes que constituían minorías en sus respectivos Ayuntamientos, el Tribunal Supremo se haya pronunciado sobre el alcance de la doctrina del Tribunal Constitucional con relación a la institución representativa dentro del ámbito municipal. En concreto, en el presente trabajo, me referiré a la respuesta que el Tribunal Supremo ha dado al derecho alegado por los concejales que constituyen minoría en sus Ayuntamientos a participar en las Mancomunidades. Jurisprudencia que analizará, en primer lugar, con relación a los fundamentos que le llevaron a desestimar el derecho alegado por los recurrentes, realizando, al socaire de dicha argumentación, algunas precisiones que sugiere la especial posición de las Mancomunidades en relación a los Municipios.

En segundo lugar me referiré, por tratarse de una cuestión que el Tribunal Supremo no plantea expresamente, al contenido inferido por el Tribunal Constitucional del art. 23.2 de la Constitución, examinando los efectos de su posible extrapolación al ámbito de la representación de los Ayuntamientos en las Mancomunidades.

\section{LA REPRESENTACION DE LOS AYUNTAMIENTOS EN LAS MANCOMUNIDADES EN LA JURISPRUDENCIA DEL TRIBUNAL SUPREMO}

El Tribunal Supremo se ha enfrentado, al menos en las sentencias de 9 de septiembre de 1988 -Ponente excelentísimo señor don Ramón Trillo Torres- y 5 de diciembre de 1988 -Ponente excelentísimo señor don Luis Antonio Burón- (4) con el posible derecho de los representantes que constituyen minoría en los Ayuntamientos, a participar en los órganos de gobiernos de las Mancomunidades como manifestación del art. 23 de la Constitución $y$ de acuerdo, todo ello, con la doctrina expuesta en la

(4) Aranzadi 7039 y 9317, respectivamente. En primera instancia conoció de ambos asuntos la Sala de lo Contencioso-Administrativo de la Audiencia Territorial de Valladolid que estimando la demanda interpuesta consideró que se había violado el artículo 23 de la Constitución, haciendo plenamente aplicable la doctrina contenida en la sentencia 32/1985, de 6 de marzo, del Tribunal Constitucional, que resume indicando "que los acuerdos que establecen la composición de una Comisión Municipal Informativa sin respetar, en lo posible, la proporcionalidad entre las distintas fuerzas políticas representadas en el Ayuntamiento, violan el derecho de los concejales de la minoría y de sus electores a participar en las funciones públicas».

La Sala Quinta del Tribunal Supremo revoca en ambos supuestos las sentencias de la Audiencia Territorial de Valladolid, por entender que no había existido tal violación del artículo 23 de la CE. 
Sentencia 32/1985 del Tribunal Constitucional. En concreto, los recurrentes entendían que el acuerdo municipal nombrando a los dos representantes del Ayuntamiento en la Comisión Gestora de la Mancomunidad infringía el art. 23 de la Norma Fundamental, por cuanto al pertenecer ambos representantes al Grupo Municipal Mayoritario, dicha resolución estaba vulnerando el derecho de los Concejales pertenecientes a la minoría a ejercer su función representativa de acuerdo con la doctrina del Tribunal Constitucional.

El Tribunal Supremo en ambas sentencias rechaza la posible aplicación de la doctrina del Tribunal Constitucional alegada, y en consecuencia entiende que no existe un derecho de los Concejales que constituyen la minoría municipal a participar de los Organos de Gobierno de las Mancomunidades.

Para llegar a tal conclusión el Tribunal Supremo se plantea. la cuestión a partir de la falta de identidad entre el supuesto que resolvió el Tribunal Constitucional-Comisión interna de un Ayuntamiento- y el supuesto que en ese momento conoce la Sala del Tribunal Supremo -órgano de una Mancomunidad-. En consecuencia, plantea la cuestión desde la perspectiva del órgano donde se reclama la participación de la minoría, siendo dos los aspectos en que justifica la inexistencia de la lesión constitucional alegada: por una parte la diferente naturaleza constitucional de las Mancomunidades que, a diferencia de los Ayuntamientos, no constituyen verdaderos entes representativos y por otra parte, la posición de las Mancomunidades frente a los Ayuntamientos que, por situarse fuera del ámbito interno de éstos, carece de relevancia la adscripción política de los representantes designados. Argumentos que se analizan más detenidamente a continuación:

A) Respecto a la primera de las cuestiones, afirma el Tribunal Supremo, que los representantes en las Mancomunidades no tienen el reconocimiento constitucional inmediato que por el contrario sí tienen los representantes en los Municipios. Así señala textualmente la sentencia de 9 de sepriembre de 1988 que "una Mancomunidad, aunque goza de la consideración de entidad local, carece de la cobertura constitucional inmediata que el art. 140 de la Constitución otorga a los representantes de los vecinos en los Ayuntamientos». Finaliza la argumentación considerando que fue en dicha cobertura constitucional donde el Tribunal Constitucional había fundamentado el amparo concedido, en la sentencia alegada por los recurrentes.

Quizás sea en dicho razonamiento donde más claramente se ponga de manifiesto la desviación argumental del Tribunal Supremo. Efectivamente, si hubiera existido un reconocimiento explícito de los representantes de las Mancomunidades dentro del 
ámbito constitucional, nos encontraríamos ante una parte integrante de la organización territorial, y en cuanto tal con un sustrato poblacional propio, de donde surgirían los representantes.

Pero, los recurrentes no estaban planteando la naturaleza territorial de las Mancomunidades, ni por ende el carácter de representación política de sus cargos (5), sino el derecho de los representantes municipales que constituyen minoría a ejercer el control de la actividad municipal, y como consecuencia de ello, a participar en las Mancomunidades.

En todo caso, la propia argumentación del Tribunal Constitucional en la Sentencia de referencia, pone en evidencia la irrelevancia del razonamiento del Tribunal Supremo. En efecto, el Tribunal Constitucional se enfrenta asimismo con la naturaleza del "órgano» donde la participación se reclama -en aquella ocasión las Comisiones Informativas-, al hilo de la argumentación del Abogado del Estado, que consideraba que las Comisiones Informativas no eran un órgano representativo, sencillamente por no ser órgano, al carecer de facultades decisorias, y por tanto no era exigible la proporcionalidad reclamada. Pero el Tribunal Constitucional, rechaza la fuerza invalidante de tal argumentación (6), entendiendo que la perspectiva desde la que había que analizar el supuesto era desde la posición del Ayuntamiento pleno cuyo acuerdo se recurría, quien sí está sometido a la efectiva materialización de la representatividad que conlleva (7).

B) El propio Tribunal Supremo parte, en el segundo de los aspectos que resalta, de este posible límite que el Ayuntamiento pleno en cuanto órgano representativo, pueda tener en la proporcionalidad reclamada. Cuestión que le sirve asimismo para resolver en punto teórico el problema de la representación en las Mancomunidades, de acuerdo con la doctrina elaborada en ateriores pronunciamientos de la propia Sala, con motivo de la designación de los

(5) En la Sentencia 23/1984, de 20 de febrero, el Tribunal Constitucional declaró que el artículo 23 se refiere a los cargos públicos de representación política, que son los que corresponden al Estado y a los entes territoriales en que se organiza territorialmente de acuerdo con el artículo 137 de la Constitución -Comunidades Autónomas, Municipios y Provincias.

(6) El Tribunal Constitucional entiende que la argumentación del Abogado del Estado se inspira "en la construcción dogmática kelseniana», si bien considera que "no le es enteramente fiel y en esa misma medida pierde también su fuerza suasoria». Tras recordar la construcción dogmática de Kelsen, en sentido estricto concluye que «de acuerdo con esta construcción dogmática, las Comisiones informativas no son órganos representativos, pero tampoco los Ayuntamientos $y$, en consecuencia, ningún argumento puede extraerse de ella para demostrar cuál haya de ser la composición de aquéllas en relación con la de éstos».

(7) Señala el Tribunal Constitucional en la sentencia cit. 32/85 que «los argumentos aducidos para combatirla no permiten por tanto invalidar la afirmación del recurrente, que paradójicamente resulta en cierto modo fortalecida por el supuesto implícito de que dichos argumentos arrancan. Este supuesto implícito es, claro está, el de que todo órgano representativo ha de reflejar en su composición el resultado de la elección popuları. 
miembros de las Asambleas Generales de las Cajas de Ahorro, que la Ley atribuye en parte a las Corporaciones locales. Según dicha doctrina hay que distinguir con carácter general entre dos ámbitos: por una parte la composición de las Comisiones internas de los Ayuntamientos, cuya designación debe sujetarse al criterio de proporcionalidad, de acuerdo con la doctrina del Tribunal Constitucional. $Y$ por otra parte la designación de representantes de los Ayuntamientos en otras entidades, que no está sujeta a criterio constitucional alguno. En este supuesto, el Tribunal Supremo entiende que el único requisito exigible es el acuerdo de la mayoría que establezca la legislación de Régimen local, al considerar que la representación exterior de los intereses municipales no pueden mostrarse fraccionada, "por cuanto es indivisible» (8).

De esta manera el Tribunal Supremo fundamenta su argumentación en dos ideas: por una parte que el criterio proporcional en cuanto elemento integrante del concepto de representación política incide únicamente en la estructuración interna de los Ayuntamientos y por otra parte parece configurar un concepto de representación genérico para todos aquellos supuestos en que los Ayuntamientos deban ser representados en otra entidad distinta, $y$ en donde no tiene cabida el límite de la proporcionalidad.

Tales afirmaciones obligan a realizar algunas precisiones, en base a la peculiar situación de las Mancomunidades en relación a los municipios. Pero para matizar su alcance resulta obligado recordar algunas coordenadas que definen la naturaleza y contenido de los citados entes (9).

Por una parte nos encontramos ante unos entes interadministrativos, de base asociativa, para la ejecución en común de obras y servicios determinados de competencia municipal (10). Desde esta

(8) La Sala Quinta del Tribunal Supremo en sentencias de 2 de febrero, 8 de julio y 4 de noviembre de 1988 -Aranzadi 1158, 8452 y 8499- ha entendido con motivo de la representación de las Corporaciones locales en los Organos Rectores que «cuando la Corporación local, como entidad, debe ser representada, cual sucede en el caso actual, la voluntad corporativa se forma con arreglo al procedimiento establecido en la legislación de régimen local, donde las decisiones se adoptan por votación mayoritarian, interés de la mayoría y de la minoría, ya que una tal exigencia sería contraria a la unidad de la persona jurídica pública de la Corporación.

(9) Con posterioridad a la actual legislación local, el tema de las Mancomunidades ha sido tratado de forma exhaustiva por Ramón MARTín MATEO. Entes Locales Complejos. Madrid. Trivium Editorial. 1987.

(10) Artículos 44 y siguientes de la Ley 7/1985, de 2 de abril, de Bases de Régimen Local. Por su parte el Texto Refundido de 18 de abril de 1986 desarrolla dicha regulación en los artículos 35 y siguientes. Por último el Reglamento de Organización, Funcionamiento y Régimen Jurídico de las Corporaciones Locales de 28 de noviembre de 1986, señala unas bases de funcionamiento para las Mancomunidades.

Seguramente la única innovación significativa de la Ley 7/1985 sea la restricción de la posibilidad asociativa al ámbito municipal excluyendo las Mancomunidades provinciales. En 
perspectiva las Mancomunidades no son sino el ejercicio mancomunado de las competencias de titularidad municipal. Por ello no se trata de la disponibilidad por parte de los Ayuntamientos de la titularidad de dichas competencias - lo que podría entenderse inalcanzable- sino de una facultad discrecional en el modo de ejercicio de sus respectivas competencias. $Y$ precisamente por cuanto es una transferencia voluntaria de ese ejercicio, los Ayuntamientos pueden revocar el mandato en cualquier momento. Desde este prisma las Mancomunidades no son sino una de las modalidades de prestación de servicios que la Ley de Bases vigente atribuye a los municipios (11). Ello permite afirmar que las Mancomunidades así vistas no son sino una modalidad de cooperación, a través de la creación de un órgano de codecisión (12).

Pero por otra parte las Mancomunidades vienen, asimismo, a configurar verdaderos entes locales, dotados de todas las potestades que la legislación atribuye a los entes de esa naturaleza (13). En consecuencia, aunque es cierto que las Mancomunidades no son una asociación de individuos, y por ello no lo son del vecindario que componen los diferentes municipios, sino de Ayuntamientos, no es menos cierto que su configuración como entes locales supone unas posibilidades de actuación que inciden y vinculan directamente no sólo a los Ayuntamientos miembros sino asimismo a los vecinos.

Por último cabe señalar la comun exigencia, pese al silencio legal en este sentido de que los representantes de los Ayuntamientos reúnan la condición de concejales (14).

congruencia con ello la Disposición transitoria novena establece el plazo de un año para la disolución de la denominada Mancomunidad de Diputaciones de Régimen Común.

Cabe por último señalar al respecto que, como consecuencia de la asunción general por los Estatutos de Autonomía, algunas Comunidades Autónomas han desarrollado legislativamente esta materia, cuya primera iniciativa fue adoptada por la Comunidad Autónoma de Aragón con la Ley 6/1987, de 15 de abril.

(11) El artículo 26 de la Ley de Bases de Régimen Local establece los servicios mínimos que deben prestar los Municipios, los cuales pueden prestarlos indistintamente por sí mismos o de forma asociada.

(12) Desde esta perspectiva podría detectarse en las Mancomunidades una manifestación de la técnica de Cooperación voluntaria, de acuerdo con el contenido, que mutatis mutandi, la doctrina ha elaborado para las relaciones Estado-Comunidades Autónomas. En este sentido Enoch ALBERTI ROVIRA «Las relaciones de colaboración entre el Estado y las Comunidades Autónomas". Revista Española de Derecho Constitucional, número 14 (mayo-agosto 1985), pp. 135 y ss.

(13) Artículos 3 y 4 de la Ley $7 / 1985$, de 2 de abril, Reguladora de las Bases del Régimen Local. Asimismo el artículo 2 de la Ley Aragonesa 6/1987, de 15 de abril, sobre Mancomunidades de Municipios, donde se determinan las potestades que corresponden a las Mancomunidades, $y$ donde se incluye incluso la potestad expropiatoria para la ejecución de obras y servicios, además de la tributaria referida al establecimiento de tasas.

(14) El artículo 44.2 de la Ley de Bases 7/1985 señala textualmente que ulos órganos de gobierno serán representativos de los Ayuntamientos mancomunados». Dicho punto de partida no permite afirmar nada respecto al efectivo contenido de dicha representación, ya que la misma redacción pero en relación a los órganos de gobierno de las comarcas, ha dado lugar a soluciones muy dispares en el desarrollo autonómico. 
Pues bien, en relación a la primera parte de la tesis del Tribunal Supremo -en base a la cual la doctrina del Tribunal Constitucional no es aplicable por tratarse de una entidad exterior al Ayuntamiento- nos encontramos con una especial posición de las Mancomunidades en relación a los municipios, que hace de algún modo sean su prolongación al no consistir aquéllas sino en el mero ejercicio mancomunado de competencias de titularidad municipal.

A mayor abundamiento hay que tener en cuenta que el ámbito decisorio de los Ayuntamientos, donde la adscripción política de los representantes adquiere relevancia jurídica, es según la doctrina del Tribunal Constitucional aquel que use adopte en ejercicio de la facultad de organización que es consecuencia de su autonomía» (15), por lo que tanto el ejercicio de esta facultad de organización puede resultar la prestación de servicios de forma mancomunada, como la creación de Comisiones Informativas en aquellas competencias que los Ayuntamientos ejerzan por sí mismos.

Respecto a la solución teórica de la cuestión, hemos indicado cómo el Tribunal Supremo parece dar a entender que, más allá de la representación política, existe un concepto único de representación, al menos en el ámbito municipal al que se refiere. Pero con ello, no resuelve realmente el problema por cuanto los intereses son o no divisibles en función, precisamente, de que exista una obligación externa al Ayuntamiento de adecuarse al criterio de proporcionalidad, y esta adecuación dependerá precisamente de la representatividad que deba hacer efectiva la representación ante la que nos encontremos. Por ello dicha unificación conceptual no resulta satisfactoria dado el diferente fundamento constitucional y legal de los distintos entes en donde los municipios deban ser representados. Diferencias que son especialmente relevantes, precisamente, en el ámbito de las Cajas de Ahorro y Mancomunidades que el Tribunal Supremo ha tenido la oportunidad de aplicar dicha doctrina y que prueban la dificultad de englobar la cuestión dentro de una categoría genérica.

Así las Cajas de Ahorro, tal como ha declarado el Tribunal Constitucional, tienen un carácter fundacional, de acuerdo con el derecho constitucional de fundación para fines de interés general -art. 34 de la Constitución-. Nos encontramos en consecuencia ante unos entes no de carácter público sino de carácter social que si bien. cumplen fines de interés público, no llegan a ejercer verdaderas funciones públicas (16). Es por ello que la Ley Orgánica

(15) Sentencia del Tribunal Constitucional 32/1985, FJ 2.

(16) En la sentencia 1/1984, de 7 de febrero de 1984, el Tribunal Constitucional liega a las siguientes conclusiones: «1) Las Cajas de Ahorros fundadas por las Corporaciones locales 
que regula los órganos rectores de las Cajas de Ahorro, ha previsto la representación de los intereses colectivos de la zona donde las Cajas se encuentran ubicadas, y entre ellas se establece una representación de las Corporaciones locales (17).

Ello hace que los representantes -para los que no se exige la condición de concejales- una vez designados por las Corporaciones locales, vengan a integrar los órganos de gobierno de las Cajas de Ahorro, de acuerdo con el status que la propia Ley define. En efecto, la mencionada Ley de las Cajas de Ahorro, establece un status jurídico homogéneo para todos los consejeros de la Asamblea General, regulando un período propio de duración para todos ellos, un sistema de incompatibilidades, y lo que es más importante, un contenido específico de sus funciones que define bajo la concreta finalidad de defender los intereses de la Caja de Ahorros (18).

En consecuencia parece que no se trata tanto de que esos miembros de la Asamblea General hagan valer los intereses de unas determinadas Corporaciones locales, como de que estos miembros son designados por las Corporaciones locales, a fin de defender los intereses de las Cajas de acuerdo con las finalidades preestablecidas. Resulta más lógico interpretar que en el caso de las Cajas de Ahorro, nos encontramos más allá del concepto de representación, fuere del tipo que fuere, para situarnos en una competencia para designar Consejeros generales de las Cajas de Ahorro.

De lo dicho queda clara la diferente posición y contenido, respecto de los Consejeros de las Cajas de Ahorro, de los representantes que integran las Mancomunidades, cuyo status y función están íntimamente ligados a la condición de concejales de los Ayuntamientos correspondientes, y cuyas competencias, dichos representantes vienen a dirigir y a controlar en esta especial forma mancomunada.

En consecuencia, incluso analizado el problema de la representación en las Mancomunidades desde la perspectiva de su posición

no tienen la naturaleza de entes públicos, sino de entes de carácter social en los términos vistos. 2) Las decisiones del Consejo de Administración en materia de elecciones no se adoptan por delegación del Estado. 3) Los miembros del Consejo de Administración, elegidos, no tienen la consideración de cargos públicos a los efectos del artículo 23 de la Constitución».

(17) Artículos 2 y 3 de la Ley $31 / 1985$, de 2 de agosto, de Regulación de las Normas Básicas sobre Organos Rectores de las Cajas de Ahorros.

(18) En el artículo 1 de la Ley 31/1985, de 2 de agosto, cit., se señala que los componentes de los Organos Rectores «ejercerán sus funciones en beneficio exclusivo de los intereses de la Caja a que pertenezcan y del cumplimiento de su función socials. En el artículo 8 se regulan las incompatibilidades de los consejeros generales y en el artículo 10 la duración del cargo. 
de entidad distinta al Municipio, es decir, desde la posición del órgano donde se reclama la participación la respuesta dada por el Tribunal Supremo, englobándola dentro de una categórica genérica no resulta satisfactoria, dadas sustanciales diferencias que existen entre los entes donde los Ayuntamientos deben ser representados. Y su respuesta adecuada debía haber tenido en cuenta las peculiaridades jurídicas de las Mancomunidades y en particular la estrecha relación que conlleva su subrogación en el ejercicio de una parcela competencial cuya titularidad permanece en el ámbito municipal.

En cualquier caso, estas particularidades jurídicas de las Mancomunidades adquieren su verdadera dimensión, dentro del planteamiento seguido por el Tribunal Constitucional en la alegada sentencia de 6 de marzo de 1985, y en concreto dentro del derecho de los representantes que constituyen minoría a ejercer su específica función, de acuerdo con el contenido del art. 23.2 de la Constitución.

\section{EL DERECHO DE LOS CONCEJALES QUE CONSTITUYEN MINORIA EN EL PLANTEAMIENTO DEL TRIBUNAL CONSTITUCIONAL}

Hemos visto, pues, cómo el Tribunal Supremo analiza en la Jurisprudencia señalada, el posible sometimiento al criterio proporcional como elemento constitutivo de la representación política: primero desde la perspectiva del órgano donde se reclama participación, y en segundo lugar como límite a la voluntad del Ayuntamiento, en cuanto órgano representativo.

Pero el Tribunal Supremo omite el análisis de la posible lesión que dicho acuerdo podía haber supuesto de algún derecho fundamental de los recurrentes, y en concreto respecto del art. 23 de la Norma Fundamental.

Efectivamente, el motivo que llevó al Tribunal Constitucional a otorgar el amparo fue, precisamente, la existencia de una lesión a un derecho fundamental de los recurrentes, única perspectiva que, en todo caso, permitía otorgar el amparo.

En concreto, el Tribunal Constitucional considera que la sujeción a dicho criterio de proporcionalidad como elemento constitutivo del concepto de representación política, no supone, en sí misma, ninguna lesión del alegado art. 23.2 de la Constitución (19). Y fue

(19) Señala la sentencia 32/1985, FJ 2, del Tribunal Constitucional, que «de esa divergencia entre la exigencia constitucional y el acuerdo municipal no se sigue, sin embargo, necesariamente, como ya señalamos antes, que el mismo haya infringido derechos fundamentales de los recurrentes, pues una cosa es que la situación constitucional de la minoría la la que la Constitución no atribuye derechos en el sentido riguroso del concepto) haya sido desconocida, y otra distinta la de que tal desconocimiento implique, además una lesión de los derechos fundamentales de quienes la componen». 
del estudio de su contenido constîucional de donde infirió la existencia de una lesión de los derechos fundamentales de cada uno de los representantes que constituían minoría en el Ayuntamiento.

De esta manera el objero de análisis queda definido por la función de los concejales pertenecientes al Ayuntamiento, teniendo en cuenta que la representatividad que deben hacer efectiva, se encuentra incidida no sólo por su condición de represetantes del Cuerpo Electoral sino asimismo por ser representantes de sus elecrores.

$Y$ dicha función, en el caso de los representantes miembros de la minoría, consiste en que la opinión "de ésta -que es el instrumento de participación en los asuntos públicos de quienes fueron sus electores-, sea oída sobre los asuntos que el órgano de que forman parte ha de conocer y resolver y lo sea, además en los diferentes estadios del proceso de decisión» (20).

Dicho contenido se integra dentro del derecho de todo representante a ejercer el control de la actividad municipal -con independencia de quién ocupe los puestos de decisión polírica- lo que conlleva en todo caso, un derecho de información de cuantos datos y antecedentes sean necesarios para las posteriores deliberaciones y decisiones en el pleno del Ayuntamiento (21). El Tribunal Constitucional, respecto al derecho a participar en las Comisiones informativas concluye afirmativamente -como es sabido-al entender que dichas Comisiones suponen un estadio importante en la preparación y conocimiento de los asuntos que debe decidir el Ayuntamiento, y en consecuencia, considera que la no participación en dichas Comisiones por parte de la minoría uhurtaría a la minoría incluso la posibilidad de participar con plena eficacia en el estadio final de la decisión» (22).

Por ello parece lógico que, el examen de la cuestión planteada ante el Tribunal Supremo respecto de las Mancomunidades, debiera haberse realizado asimismo desde esta perspectiva: si la designación, en las Mancomunidades, de concejales pertenecientes únicamente del grupo mayoritario conlleva una lesión, en sí misma, del derecho de los concejales que constituyen minoría, a ejercer su función constitucional. Aspecto que el Tribunal Supremo no ha afrontado con claridad.

(20) Sentencia 32/1985, del Tribunal Constitucional, FJ 3

(21) Dentro de este contexto se encuentran los pronunciamientos del Tribunal Supremo -Sala Quinta- en relación al derecho de los Concejales de obtención de información necesaria obrante en el Ayuntamiento para el cumplimiento de su función, como manifestación del artículo 23 de la Constitución: sentencias de 8 de noviembre de 1988 -Aranzadi 8655- y 7 de diciembre de 1988 -Aranzadi 9335-, entre otras.

(22) Sentencia 32/1985, del Tribunal Constitucional, cit. 
Prima facie, podría concluirse, que no existe tal lesión. En efecto, parece claro que desde el momento en que determinadas competencias son asumidas por las Mancomunidades, quedan sustraídas del ámbito decisorio del Ayuntamiento. En consecuencia, su configuración como un derecho a ejercer la función de control de la actuación municipal, en todo lo que concierne al Ayuntamiento, permite que al no integrar, ya, el ámbito decisorio de éste la ejecución de un determinado servicio, se pudiera concluir que no existe un derecho de control sobre dicho ámbito tal como lo ha configurado el Tribunal Constitucional.

Pero si se examina con mayor detenimiento, la regulación local, se puede llegar a una conclusión muy diferente. Examen que exige recordar, previamente, algunos aspectos del ámbito local.

Por una parte hay que tener en cuenta que la propia construcción del gobierno local como representativo, se fundamenta sobre la idea de que ha de ser la colectividad local la que asuma la gestión de sus propios asuntos a través de representantes por ella. Y dichos asuntos propios son definidos por la Ley de Bases vigente a través de un elenco de competencias que configuren en algunos casos el contenido mínimo de autonomía, y cuya prestación, como se ha dicho más arriba pueden o bien llevarla a cabo por sí o de forma mancomunada (23). Pero en cuya gestión los representantes deben hacer efectiva, en todo caso, la participación de la colectividad local. En este sentido las Mancomunidades vienen a gestionar por mandato de los Ayuntamientos una parcela de ese interés de la colectividad local, lo que supone la sustracción de un ámbito decisorio de los Ayuntamientos -al menos mientras dicho mandato se mantenga -para atribuírselo a los órganos de gobierno de las Mancomunidades.

$Y$ por otra parte ese trasvase de competencias, conlleva, como ya se ha dicho, la configuración de un nuevo ente local con todas las potestades administrativas necesarias para poder ejercer las competencias correspondientes, lo que supondrá en última instancia una vinculación directa entre el vecindario y el nuevo ente local.

Es este el prisma, en consecuencia, desde donde cabe plantearse la cuestión analizada. Es decir, si la intervención -por declaración legal-, de los Municipios en unas materias -que configuran su garantía institucional-, constituye en sede de la representación política, el ámbito de actuación municipal sobre el que los representantes pueden ejercer su función constitucional. $Y$ en consecuencia si la sustracción de ese ámbito de decisión sobre una materia, mediante su trasvase a una Mancomunidad, puede

(23) Artículo 26 de la Ley de Bases de Régimen Local, de 2 de abrit de 1985. 
llegar a suponer -en el caso de que no tenga efecto ref́lejo en la representación- un vaciamiento del contenido que han de desempeñar los concejales que constituyen minoría.

Planteada así la cuestión, no parece descabellado pensar que sí existe un derecho de la minoría a tener iguales "condiciones de acceso al conocimiento de los asuntos y de participación en los distintos estadios del proceso de decisión», con motivo análogo -y con mayor razón- ese derecho a ejercer el control municipal, puede conllevar un derecho a participar en aquellos órganos que materializan las competencias municipales de forma mancomunada. Efectivamente, si ese derecho existe respecto a las Comisiones informarivas -que son sólo un estadio previo a la decisión en el Pleno-, con más morivo debería existir respecto a unos órganos que tienen potestades decisorias en materia que competen al Ayuntamiento.

El problema se acrecentaría si se diera el supuesto -jurídicamente posible- de que algunos Municipios llegaran a gestionar de forma mancomunada la mayoría de las materias esenciales determinadas por la Ley del Régimen Local (24). Si así fuese, los concejales pertenecientes a la minoría podrían llegar a ver cómo su participación en los asuntos municipales, tal como to ha entendido el Tribunal Constitucional, se vaciaba de contenido, teniendo su participación un carácter meramente formal.

En realidad, la existencia de un posible derecho de los representantes que constituyen minoría a participar en las Mancomunidades, parece latir en la propia tesis expuesta por el Tribunal Supremo, aunque no llegue a analizarlo. De esta manera en la sentencia comentada de 9 de septiembre de 1988, el Tribunal Supremo señala que es la composición numérica lo que impide el ejercicio del derecho de la minoría. Así, en dicha sentencia, el Tribunal Supremo, tras rechazar la aplicación de la doctrina del Tribunal Constitucional por tratarse de supuestos diferentes, señala textualmente que "existe en el caso que ahora se enjuicia una notable diferencia, determinada por la composición numérica de la Comisión gestora de la Mancomunidad, que hace que cada Ayuntamiento sólo pueda designar a dos concejales representantes del mismo. Ante esta circunstancia, la regla de la proporcionalidad quiebra cualitativamente...».

De esta manera viene a declarar la imposibilidad de aceptar la proporcionalidad alegada por cuanto el número de representantes

(24) El único límite que establece el Texto Refundido de 18 de abril de 1986 es la imposibilidad de que las Mancomunidades asuman la totalidad de las competencias de los respectivos municipios -artículo 35.2-. En ese caso, como señala el Consejo de Estado -Dictamen 43.749, de 17 de diciembre de 1981- nos encontraríamos ante una fusión más que ante una asociación. Todo ello supone que no impide el legislador que se gestionen la mayoría de las competencias o las fundamentales a través de las Mancomunidades. 
a designar por cada Ayuntamiento -dos- no permite esa posibilidad, ya que ello supondría aceptar un derecho de igualdad, que en modo alguno puede definir las relaciones entre la mayoría y la minoría de un Ayuntamiento. Es decir, el Tribunal Supremo parece aceptar que un elemento circunstancial puede incidir cualitativamente en el contenido de un derecho fundamental.

En consecuencia el Tribunal Supremo, pese al previo rechazo de la existencia de un derecho ubicado en el art. 23.2 de la Norma Fundamental, y sin que lo llegue a justificar, se da cuenta de que puede existir, efectivamente, tal derecho, si bien no se puede materializar. Por ello, pese a su negación primera, pone de manifiesto la tensión del derecho de la minoría a participar mediante el control de la actividad, y el de la mayoría a ocupar los puestos de decisión política. Lo que parece ocurrir es que el Tribunal Supremo opta por esta última, sencillamente por cuanto entiende que la composición numérica elegida por los Ayuntamientos no permite otra alternativa.

En definitiva, el Tribunal Supremo no se plantea expresamente lo que debería haber configurado la cuestión fundamental del tema debatido, consistente en conocer en qué medida ese derecho de la minoría, puede llegar a condicionar el sistema de elección de dichos representantes 0 , incluso, a modular la composición numérica, a fin de que pueda adecuarse al criterio de proporcionalidad. Composición que, en todo caso, viene determinada por los propios Estatutos de las Mancomunidades, los cuales, como es sabido, se aprueban por acuerdo de los Ayuntamientos mancomunados.

Por ello no parecería fuera de lugar, pensar que si se aplicara con todo su rigor el derecho de los concejales que constituyen minoría, establecido en el art. 23.2 de la Norma Fundamental, tal como lo ha interpretado el Tribunal Constitucional, su alcance llegara a exigir un determinado sistema de elección -regla D'Hondt- o a modular la composición numérica, y exigir una composición que permitiera hacer efectivo tal derecho.

\section{CONCLUSION}

El examen de la argumentación que el Tribunal Supremo realiza sobre la representación de los Ayuntamientos en las Mancomunidades, y sobre el derecho de los concejales que constituyen minoría en dichos Ayuntamientos, pone de manifiesto una postura ambigua del Tribunal Supremo, ya manifestada en anteriores ocasiones (25), en virtud de la cual parece someter la efectividad

(25) Resulta, asimismo, ejemplo de interẻs la propia sentencia de 14 de junio de 1984, de la Sala Tercera del Tribunal Supremo -Aranzadi 3204-, que dio lugar, tras la interposición del 
de tal derecho constitucional al alcance que la normativa vigente llegue a permitir. Cuando lo jurídicamente coherente exige, más bien, que sea ésta la que deba someterse al contenido esencial de los derechos fundamentales, que directamente de la Constitución se infiere, de acuerdo lógicamente, con la interpretación del Tribunal Constitucional (26).

En todo caso, la definitiva respuesta necesitaría de un pronunciamiento del Tribunal Constitucional que afrontara con mayor decisión los problemas que se plantean en la representación municipal en las Mancomunidades, ya que a la vista de los pronunciamientos analizados del Tribunal Supremo, no parece probable que éste vuelva sobre la cuestión desde una diferente perspectiva jurídica, parece que el Tribunal Supremo ha dejado zanjada la cuestión, y resulta ilógico pensar que pueda llegar a replantearse la cuestión con una mayor profundidad de planteamientos (27).

oportuno recurso de amparo, a la tan aludida sentencia 32/1985, de 6 de marzo. Señala dicha sentencia que «el acceso en condiciones de igualdad a las funciones y cargos públicos está subordinado a los requisitos que señalan las leyes y en el caso presente la designación de las comisiones municipales se rige por las normas de los acuerdos municipales que, según el artículo 302 de la Ley de Régimen Local de 24 de junio de $1955 \ldots$ se adoptan por mayoría de votosi).

(26) Como es sabido el artículo 53.1 de la Constitución establece que "sólo por ley, que en todo caso deberá respetar su contenido esencial, podrá regularse el ejercicio de tales derechos y libertades").

(27) Una vez finalizado el presente trabajo compruebo que el Tribunal Constitucional en sentencia 76/1989, de 27 de abril, se ha pronunciado sobre el problema de la designación de los Senadores que representan a las Comunidades Autónomas. Me parece de interés hacerme eco de su contenido, pues a pesar de las diferencias que evidentemente existen entre el ámbito allí analizado y el aquí estudiado, entiendo que pueden resultar útiles sus conclusiones de cara al alcance que, en su caso, conllevaría la institución representativa.

Entre las cuestiones suscitadas en sede del Tribunal Constitucional se planteaba la posible vulneración del artículo 23.2 de la Constitución, al haber resultado designados los dos Senadores pertenecientes al grupo parlamentario mayoritario, lo cual en opinión del recurrente no respetaba las exigencias de proporcionalidad.

Pues bien el Tribunal Constitucional entiende que al resultar de aplicación el Régimen Electoral General -Ley 5/1985- se respetan las exigencias derivadas del principio de proporcionalidad con la aplicación de la regla D'Hondt, a pesar de que uen el presente caso la aplicación del criterio de proporcionalidad se ha traducido en representación mayoritaria de un sólo grupo político. pero ello es consecuencia de la dificultad de alcanzar la proporcionalidad en la representación cuando el abanico de posibilidades, dado por el número de puestos a cubrir, en relación con el de las fuerzas concurrentes, es muy reducido").

Dicha doctrina supone una expresa superación del criterio del Tribunal Supremo para quien, como hemos visto, resulta imposible dar entrada al criterio proporcional cuando la composición numérica queda limitada a dos representantes.

En el caso presente, pues, en el supuesto de encontrarnos ante un derecho de los concejales que son minoria, tal como he defendido en el trabajo, éste podría materializarse en la exigencia de dicho sistema de eleccion, con independencia del resultado. Si bien existe una diferencia entre uno y otro ámbito, que podría ser sustancial, ya que en el caso de los Senadores se trata de una limitación cuantitativa ex artículo 69.5 de la Constitución, y en el caso analizado en el trabajo, la composición numérica depende del acuerdo de los Ayuntamientos -en este aspecto. más cercano a las Comisiones Informativas-, y por ello, con unas mayores posibilidades de adecuación al criterio de proporcionalidad. 